\title{
Discharge Destination from Acute Care after Traumatic Brain Injury
}

\author{
Hwan Kim, Angela Colantonio, Raisa Deber, Lee Vernich
}

\begin{abstract}
Objective: To identify the impact of private insurance coverage on discharge disposition after a traumatic brain injury (TBI) using injury in a motor vehicle accident (MVA) as a proxy for private insurance, controlling for age and severity of injury. Method: Cross-sectional study. Patients: Patients with TBI discharged between 1993-1994 and 2000-2001 (n = 9,703). Main Outcome Measure: Discharge destination from acute care; controlled odds ratio (OR) and confidence interval (CI) for type of injury. Results: Type of injury, age, and length of stay are significantly associated with discharge destination. However, the motor vehicle accident patients are $56 \%$ more likely to be discharged to home with support services than patients with similar injuries from falls. Conclusion: Even in a system with universal coverage, availability of private insurance type is a potential independent determinant of postacute care services. More research is required to determine the effect this relationship has on the cost and outcomes of care for TBI patients.
\end{abstract}

RÉSUMÉ: Orientation des traumatisés cérébraux au congé d'une institution de soins de courte durée. Objectif: Identifier l'impact d'une couverture par une assurance privée sur l'orientation des patients au congé d'une institution de soins actifs après un traumatisme crânien (TC). Un traumatisme subi lors d'un accident de la route a servi d'indicateur de substitution pour l'assurance privée, après ajustement pour l'âge et la sévérité de la lésion. Méthode: Il s'agit d'une étude transversale. Patients: Les patients ayant subi une lésion cérébrale par traumatisme crânien qui ont reçu leur congé d'un hôpital de soins de courte durés entre 1993-1994 et 2000-2001 (n = 9703 ). Critère d'évaluation principal: L'orientation au congé était l'issue principale; le rapport de cotes et l'intervalle de confiance ont été ajustés pour le type de lésion. Résultats: Il existait une association significative entre l'orientation au moment du congé et le type de lésion, l'âge du patient et la durée de l'hospitalisation. Cependant, les patients qui ont subi un accident de la route sont $56 \%$ plus susceptibles d'être retournés à domicile avec des services d'appoint que les patients qui ont subi des lésions similaires à cause d'une chute. Conclusion: Même dans un système où il existe une couverture universelle des soins de santé, la disponibilité d'une assurance privée peut être un déterminant indépendant des services après la période de soins aigus. Son influence sur le coût et l'issue des soins chez les TC devront faire l'objet de recherches plus poussées.

Can. J. Neurol. Sci. 2006; 33: 48-52

Treatment for traumatic brain injury (TBI) is expensive, and availability of insurance coverage not surprisingly influences which treatments can be provided. In the United States, where insurance coverage is not universal, researchers have found that persons with TBI who were insured by commercial fee-forservice plans were more likely to get post-acute care in rehabilitation facilities. ${ }^{1}$ It has been assumed that in countries such as Canada, where health insurance is universal, similar barriers would not exist.

However, only $70 \%$ of Canadian health expenditures are funded publicly through a series of provincial insurance plans that provide universal coverage without co-payments. Coverage extends to all insured services provided to insured persons. Because the Canada Health Act defines insured services in terms of 'medically required' care provided in hospitals, or by physicians, there is no legal requirement to insure care by non- physicians provided in the community. Accordingly, the publicprivate mix varies extensively by sub-sector, and across provinces. $^{2}$ Rehabilitation services are particularly vulnerable. ${ }^{3}$ The Canadian Institute for Health Information estimates that about $99 \%$ of expenditures for physician services, and about $90 \%$ of hospital expenditures, are paid from public sources; this

From the Graduate Department of Rehabilitation Science (HK), Department of Health Policy, Management and Evaluation (RD), Department of Public Health Sciences (LV), Department of Occupational Therapy, Toronto Rehabilitation Institute (AC), University of Toronto, Toronto, ON, Canada.

Received October 15, 2004. AcCePted in Final Form SePtember 10, 2005. Reprint requests to: Angela Colantonio, Department of Occupational Therapy, University of Toronto, 500 University Ave., Toronto, Ontario, M5G 1V7, Canada. 
percentage declines considerably when one moves to other health professionals, home care, and outpatient pharmaceutical drugs. ${ }^{4}$ No private insurance is permitted for insured services, which are expected to be fully paid from the public plans. Provinces are free to insure other services, but are not required to do so. Provinces may also choose to target certain groups for extended coverage; for example, some provinces extend varying degrees of coverage for such services as out-patient pharmaceuticals or rehabilitation to varying combinations of the elderly (those over 65), the poor (those on social assistance), those with particular diseases (e.g., HIV/AIDS, cancer), and/or those receiving home care services. A number of recent examinations of the Canadian system have called for modernizing these rules, ${ }^{2,5,6}$ but to date this has not occurred. Therefore, as care moves from hospital to home and community, many services thus have the potential to escape from public financing, ${ }^{7,8}$ and may be inaccessible to certain groups with TBI.

To the extent that the publicly-financed sector has been reducing the availability of services, individuals with TBI may fall back upon private coverage, or do without services. Among the sources of private financing are two quasi-public streams Work Safety and Insurance Board and mandatory automobile insurance. In addition, some individuals have private insurance through their workplaces. In Ontario, payments through the Work Safety and Insurance Board and automobile insurance is relatively open-ended and the current legal framework makes it difficult for auto insurers to deny care. In contrast, private employer-based insurance is increasingly capping available benefits to a specified dollar amount per year. ${ }^{9}$ As Hoppe et al ${ }^{10}$ have noted, there is the potential for great differences in the funds available for similar injuries, depending upon how that injury was received.

As such, good data is difficult to obtain; however, one can use the mechanism of injury such as motor vehicle accident (MVA) as a proxy for the availability of private insurance, recognizing that an unspecified proportion of individuals with other injuries may also have private coverage.

Aim: The overall aim of this study is to examine whether individuals injured in MVA are more likely to receive more postacute care compared to those injured by other mechanisms. To do so, we will examine the differences in discharge destination between two major types of injury, MVA versus falls, controlling for age and severity of injury. For the study, we will examine one diagnostic group, traumatic brain injury, for which MVA is a major cause. Motor vehicle accident will be a proxy for private insurance while TBI due to falls will be considered injuries for which only public funding is available.

\section{Methods}

Data source: The Ontario Trauma Registry (OTR) was developed to provide comprehensive, accurate and timely population-based information about injury in the province of Ontario. This validated provincial database identifies, describes, and quantifies traumatic brain injury in the province of Ontario, including risk factors and type of injury. It is intended to provide a scientific basis to injury prevention programs, evaluate preventive measures and legislative changes, and aid in decisions regarding resource allocation.
The registry consists of three databases: the Minimal Data Set (MDS), the Comprehensive Data Set (CDS), and the Death Data Set (DDS). ${ }^{11}$ This research will focus on the use of the MDS. The MDS includes the demographic, diagnostic, and procedural information on all patients admitted to acute care hospitals in the province because of injury. Our analysis covers the fiscal years of 1993-1994 and 2000-2001.

The variables measured were the following:

- Age

- Sex

- Type of injury (MVA, Falls)

- Discharge destination

- Length of stay in hospital (LOS)

- Injury Severity Score (ISS)

The discharge destination can be any of the following:

- Inpatient hospital care (includes other acute, sub-acute, psychiatric, rehabilitation, cancer centre/agency, pediatric hospital, etc.)

- Long-term-care facility (personal care homes, auxiliary care, nursing homes, extended care, homes for the aged, seniors' homes, etc.)

- Other (palliative care/hospice, addiction treatment center, etc.)

- Home setting with support services (senior's lodge, attendant care, homecare, meals on wheels, homemaking, supportive housing, etc.)

- Home without support services

For this study, we concentrate upon discharge to home, with or without supports.

Participants: Persons 15-64 years-of-age who have had an acute hospital admission between the years of 1993-1994 and 2000-2001 for TBI as defined by the ICD-9-CM (International Classification of Diseases, 9th version, Clinical Modification) codes. ${ }^{12}$ Older individuals have more comorbidities such as heart disease, diabetes, hip fractures, which might affect their discharge planning. They are also eligible for government-paid coverage for particular services which are not generally available to those under age 65 . To avoid these potentially confounding factors, persons 65 and over were excluded from the analysis.

Analysis: Descriptive analysis was used to assess frequency distributions, means and medians. Chi-square test and MannWhitney test were used to test differences between the two types of injury groups, MVA and falls. In addition, multiple logistic regression analyses were used to identify the factors independently associated with discharge destination as the primary outcome variables. These categories reflect care that may be medically required, but is not part of the services required to be covered under the Canada Health Act. To increase homogeneity, this study was restricted to the two mechanisms of injury, MVA and falls, which had the largest sample size; we excluded all other mechanisms of injury, comprising about $16 \%$ of total TBI population, from the MDS data. Analysis used logistic regression to model type of injury (MVA/Falls) controlling for age and severity of injury.

We also categorized the injury groups into mild vs. moderate/severe using the cut-off based on LOS in hospital, since people with mild TBI are often admitted for 24 to 48 hours and then discharged home. Mild injury is thus defined as LOS 
equal or less than two days; over two days in hospital were categorized into the moderate/severe injury group. Our analysis was performed using SPSS Version 12.0.

\section{RESUlTS}

The variables used in this study are summarized in Table 1. Motor vehicle accident comprises $62 \%$ of total eligible cases. The mean age of MVA patients was about ten years younger than patients injured due to falls $(p<0.001)$. There was no significant difference in sex, with male patients comprising about two thirds of both groups. Injury severity score (ISS) was also not significant between two types of injury groups. The LOS was about one day longer for MVA patients $(p<0.001)$. However, sex and ISS scores of both groups were not significantly different $(0.671,0.225$ respectively).

In general, most patients were discharged to home with no support services. There was a small, but highly statistically significant difference in the probability of being discharged to home with such services if the injury resulted from a fall $(4.2 \%)$ or from a MVA (5.9\%). This difference disappeared if one controlled for severity (Table 2). As expected, 5008 patients out of $5046(99.2 \%)$ of the mild injury group, were discharged home without supports. For this mild injury group, only $0.6 \%$ of falls and $0.9 \%$ of MVA were discharged to home with supports.
However, for the moderate/severe groups, $8.7 \%$ of falls and $10.8 \%$ of MVA were discharged to home with supports.

As can be seen in Table 3, multiple logistic regression analysis revealed that types of injury, age, and length of stay (LOS) were significantly associated with discharge destination. The MVA patients are $56 \%$ more likely to be discharged to home with support services than patients with similar injuries from falls. The likelihood of receiving support increases by $3.5 \%$ for each extra day spent in the hospital and also increases by $9 \%$ for each age group.

For mild injury, there was no significant difference on receiving post-acute care supports regardless of mechanism of injury. Only the age and LOS were significant for the mild injury group. For the moderate/severe injury group, however, the MVA patients were still $35 \%$ more likely to be discharged to home with support services than the falls patients were.

\section{DiscuSSION}

As would be expected, type of injury, age and LOS are associated with the discharge destination of the TBI population under 65 years of age; those more severely injured are more likely to obtain extended care services. However, MVA patients are more likely to be discharged to home with support services than are falls patients; the probability of discharge to home

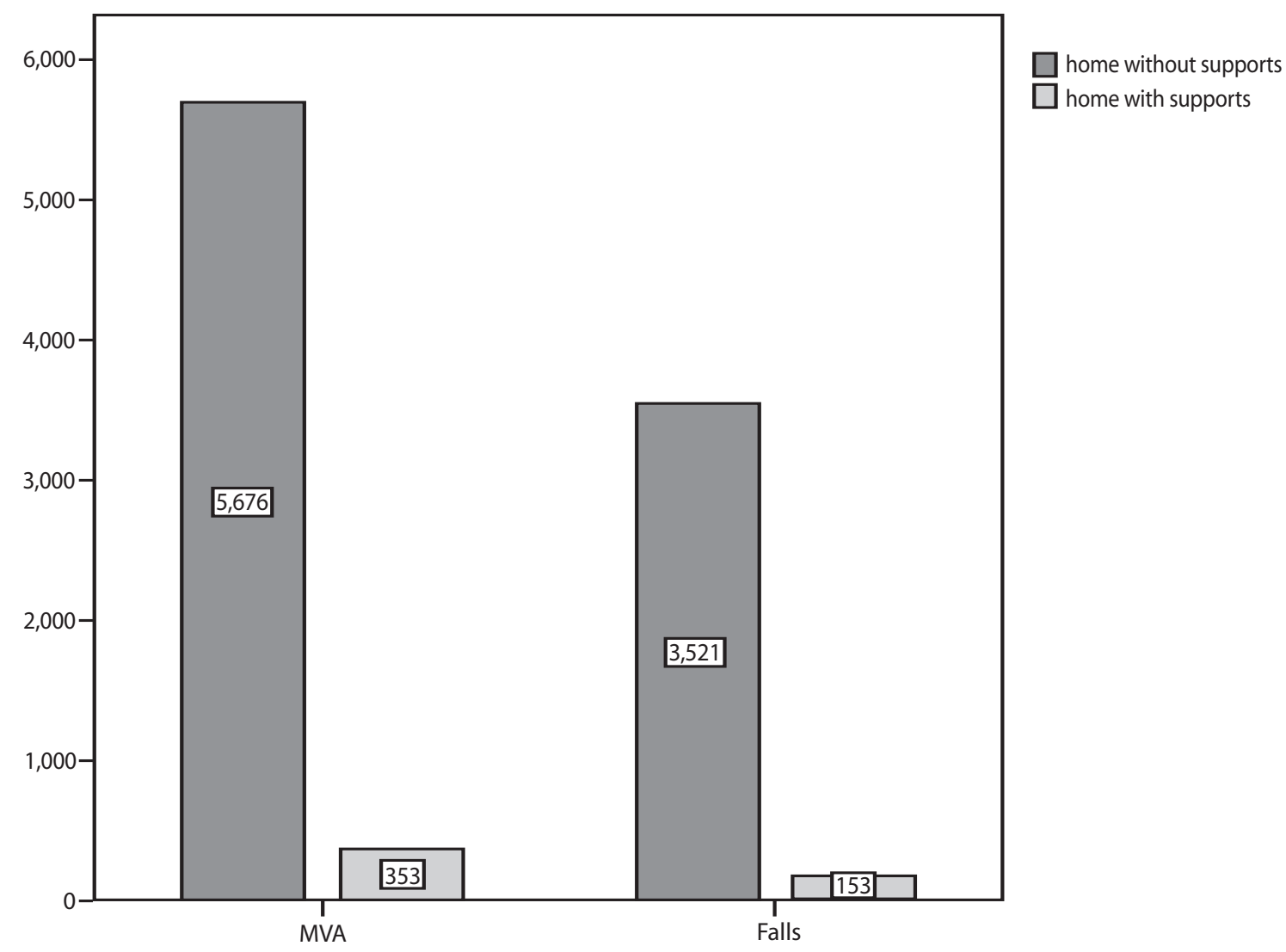

Figure 1: Discharge destination by types of injury. 
Table 1: Key variables by type of injury

\begin{tabular}{|c|c|c|c|}
\hline Variable & $\begin{array}{c}\text { MVA } \\
(n=6,029)\end{array}$ & $\begin{array}{c}\text { Falls } \\
(n=3,674)\end{array}$ & $\mathrm{p}$-value \\
\hline \multicolumn{4}{|l|}{ Age $\quad(n=9,703)$} \\
\hline Mean & 29.3 & 38.8 & \multirow[t]{2}{*}{$<0.001$} \\
\hline Median (age group) & $25-29 \mathrm{yr}$ & $40-44 \mathrm{yr}$ & \\
\hline \multicolumn{4}{|l|}{ Sex $\quad(n=9,703)$} \\
\hline Male & $4,094(67.9 \%)$ & $2,479(67.5 \%)$ & \multirow[t]{2}{*}{0.671} \\
\hline Female & $1,935(32.1 \%)$ & $1,195(32.5 \%)$ & \\
\hline \multicolumn{4}{|l|}{ Discharge destination $(n=9,703)$} \\
\hline Home setting with support services & $353(5.9 \%)$ & $153(4.2 \%)$ & \multirow[t]{2}{*}{$<0.001$} \\
\hline Home without support services & $5,676(94.1 \%)$ & $3,521(95.8 \%)$ & \\
\hline \multicolumn{4}{|l|}{ LOS in days $(n=9,703)$} \\
\hline Mean (median) & $6.3(3)$ & $4.9(2)$ & $<0.001$ \\
\hline \multicolumn{4}{|l|}{ ISS $(n=7,869)^{*}$} \\
\hline Mean (median) & $9.5(9)$ & $9.3(9)$ & 0.225 \\
\hline
\end{tabular}

Note. Chi-square test for Sex and Discharge destination. Mann-Whitney test for Age groups, LOS and ISS.

* $1,834(18.9 \%)$ cases missing for coding ISS.

without support was 1.6 times greater for falls patients than MVA patients, controlling for age and severity of injury. Even in a system with universal coverage, the availability of private automobile insurance makes a difference in obtaining supports from non-physician providers in the home.

Given the growing tendency to treat outside of acute care hospitals, these variations may be problematic for client outcomes. More research needs to be conducted to assess the longer-term impact of insurance type on service use and client outcomes. Conclusively, our study indicates that insurance type will be a potential independent determinant of acute care, and more efforts must be made to determine the effect this relationship has on the cost and outcomes of care for TBI patients.

Limitations: The minimal dataset did not include some potential information, also other socio-demographic variables

Table 2: Key variables by type of injury: mild vs. moderate/severe injury

\begin{tabular}{|c|c|c|c|c|c|c|}
\hline \multirow[t]{2}{*}{ Variables } & \multicolumn{3}{|c|}{ Mild $(\mathrm{LOS} \leq 2, \mathrm{n}=5,046)$} & \multicolumn{3}{|c|}{ Moderate/Severe $(\operatorname{LOS}>2, \mathrm{n}=4,657)$} \\
\hline & MVA & Falls & p-value & MVA & Falls & p-value \\
\hline Number & $2,996(59.4 \%)$ & $2,050(40.6 \%)$ & & $3,033(65.1 \%)$ & $1,624(34.9 \%)$ & \\
\hline \multicolumn{7}{|l|}{ Age $\quad(n=9,703)$} \\
\hline Mean (year) & 17.6 & 35.8 & $<0.001$ & 31.1 & 42.7 & $<0.001$ \\
\hline Median (age group) & $25-29 \mathrm{yr}$ & $35-40 \mathrm{yr}$ & & $30-34 \mathrm{yr}$ & $45-49 \mathrm{yr}$ & \\
\hline \multicolumn{7}{|l|}{ Sex $\quad(n=9,703)$} \\
\hline Male & $2,034(67.9 \%)$ & $1,377(67.2 \%)$ & 0.603 & $2,060(67.9 \%)$ & $2,479(67.5 \%)$ & 0.974 \\
\hline Female & $962(32.1 \%)$ & $673(32.8 \%)$ & & $973(32.1 \%)$ & $522(32.1 \%)$ & \\
\hline \multicolumn{7}{|l|}{ Discharge destination $(n=9,703)$} \\
\hline Home setting with support services & $26(0.9 \%)$ & $12(0.6 \%)$ & 0.320 & $327(10.8 \%)$ & $141(8.7 \%)$ & 0.024 \\
\hline Home without support services & $2,970(99.1 \%)$ & $2,038(99.4 \%)$ & & $2,706(89.2 \%)$ & $1,483(91.3 \%)$ & \\
\hline \multicolumn{7}{|l|}{ LOS in days $\quad(n=9,703)$} \\
\hline Mean (median) & $1.3(1)$ & $1.3(1)$ & 0.288 & $11.3(7)$ & $9.4(6)$ & $<0.001$ \\
\hline \multicolumn{7}{|l|}{ ISS $(n=7,869)^{*}$} \\
\hline Mean (median) & $9.5(9)$ & $9.5(9)$ & 0.693 & $9.5(9)$ & $9.1(9)$ & 0.023 \\
\hline
\end{tabular}

Note. Chi-square test for Sex and Discharge destination. Mann-Whitney test for Age groups, LOS and ISS.

$* 1,834(18.9 \%)$ cases missing for coding ISS. 
Table 3: Multiple logistic regression results: modelling the probability of discharge to home with supports

Total $(\mathrm{N}=7,869)$

\begin{tabular}{|c|c|c|c|c|c|c|c|c|c|}
\hline \multirow{3}{*}{$\begin{array}{l}\text { Independent } \\
\text { Variables * }\end{array}$} & \multirow[b]{3}{*}{$\mathrm{p}$-value } & \multirow{2}{*}{\multicolumn{2}{|c|}{ 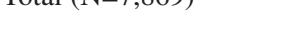 }} & \multirow{2}{*}{\multicolumn{3}{|c|}{ Mild $(\operatorname{LOS} \leq 2, \mathrm{n}=4,115)$}} & & & \\
\hline & & & & & & & \multicolumn{3}{|c|}{ Moderate/Severe $(\operatorname{LOS}>2, n=3,754)$} \\
\hline & & OR & $95 \% \mathrm{CI}$ & p-value & OR & $95 \% \mathrm{CI}$ & p-Value & OR & $95 \% \mathrm{CI}$ \\
\hline MVA/Fall & $<0.001$ & 1.559 & $1.237-1.966$ & 0.197 & 1.669 & $0.776-3.635$ & 0.020 & 1.345 & $1.048-1.726$ \\
\hline Male & 0.919 & 0.989 & $0.796-1.228$ & 0.057 & 0.503 & $0.247-1.022$ & 0.623 & 1.059 & $0.842-1.333$ \\
\hline Age & $<0.001$ & 1.089 & $1.050-1.130$ & 0.018 & 1.163 & $1.026-1.318$ & 0.085 & 1.036 & $0.995-1.078$ \\
\hline LOS & $<0.001$ & 1.035 & $1.029-1.041$ & 0.043 & 2.094 & $1.025-4.278$ & $<0.001$ & 1.019 & $1.013-1.024$ \\
\hline ISS & 0.752 & 0.998 & $0.983-1.013$ & 0.115 & 0.950 & $0.890-1.013$ & 0.755 & 1.002 & $0.987-1.018$ \\
\hline
\end{tabular}

* Variables entered the Model : type of injury(MVA), sex(Male), age, LOS and ISS

such as socio-economic status, ethnicity, previous head injury and co-morbidity were not available at the time of this study. We tried to minimize the effect of comorbidity by restricting the sample to $<65$ years of age.

In addition, OTR data do not include insurance types, such as private insurance, that could inform the results. As well, we did not capture whether patients with falls have private insurance; we may be underestimating the effects when considering that the trend of release to home and community has increased.

However, this study provides exposure to the strengths and weaknesses of using existing data registries for this type of research. It is also anticipated that recommendations will be made regarding the utility of using the OTR for the TBI research.

\section{ACKNOWLEDGEMENTS}

This study was funded by the M-THAC Research Unit, the Ontario Neurotrauma Foundation. We thank the Canadian Institute for Health Information for providing necessary data for the study.

\section{REFERENCES}

1. Chan L, Doctor J, Temkin N, et al. Discharge disposition from acute care after traumatic brain injury: the effect of insurance type. Arch Phys Med Rehabil. 2001:1151-4.

2. Standing Senate Committee on Social Affairs, Science and Technology (2001): The Health of Canadians: The Federal Role. The story so far: Interim report on the state of the health care system in Canada. Vol. 1. Ottawa, Ontario: Government of Canada.
3. Landry M. Physical therapy services in Ontario: Assessing a changing public/private mix. Ph.D. Dissertation, Department of Health Policy, Management, and Evaluation, University of Toronto (Toronto, Canada); 2005.

4. Canadian Institute for Health Information. National Health Expenditure Trends, 1975-2003; www.cihi.ca. Last updated June 4, 2004; accessed Sept. 2004.

5. Commission on the Future of Health Care in Canada (Roy J Romanow Commissioner). Building on Values: The Future of Health Care in Canada: Final Report. Ottawa: Queen's Printer, 2002.

6. Standing Senate Committee on Social Affairs, Science and Technology (2002): The Health of Canadians: The Federal Role. Recommendations for reform: Final report on the state of the health care system in Canada. Vol. 6. Ottawa, Ontario: Government of Canada.

7. Deber R. Health care reform: Lessons from Canada. Am J Pub Health. 2003; 93:20-4.

8. Deber R. Delivering health care: public, not-for-profit, or private? The fiscal sustainability of health care in Canada. Toronto: University of Toronto Press, 2004:233-96.

9. Landry M, Williams A, Deber R, et al. Market failure in Ontario's home and community sector: The case of publicly funded physical therapy services. Quebec City, Quebec: Canadian Physiotherapy Association Congress, May 30th, 2004.

10. Hoppe E, Rowat B, Verrier MC. A black box: the rehabilitation clinic. Physiother Can. 1996;48(1):106-17.

11. Canadian Institute for Health Information. Ontario Trauma Registry 2001a Report. Hospital Injury Admissions. Ottawa: Canadian Institute for Health Information, 2001.

12. ICD-9-CM: The International Classification of Diseases, 9th version, Clinical Modification. Available from: http://www.cs.umu.se/ medinfo/ICD9.html. Jul. 1996. 